\title{
Gross Target Volume
}

National Cancer Institute

\section{Source}

National Cancer Institute. Gross Target Volume. NCI Thesaurus. Code C112913.

The gross palpable or visible/demonstrable extent and location of malignant growth. 